\title{
Effects of Amalgam Restorations on the Periodontal Membrane in Monkeys
}

\author{
Carlos F. Nasjleti, Walter A. Castelli, and Raul G. Caffesse \\ Veterans Administration Hospital and the University of Michigan, Ann Arbor, Michigan \\ 48105, USA
}

The response of the periodontal membrane to reimplanted teeth carrying amalgam restorations in the middle third of their roots was studied from seven days to six months after grafting. The study revealed that the amalgam restorations produced an initial localized inflammation in the periodontal tissues that subsided subsequently with the formation of a. pseudocapsule.

\section{J Dent Res (56)9: 1127-1131 September 1977.}

Numerous histologic investigations have been done in the past to study the biological reactions to experimental dental amalgams. ${ }^{1-15}$ Dixon and Rickert ${ }^{1}$ implanted amalgam pellets into the subcutaneous connective and muscle tissues of rabbits and reported that the amalgam caused an active chronic inflammation of the adjacent tissues. However, Mitchell, ${ }^{2}$ in a study using rats, showed that amalgam prompted a moderate degree of inflammation in the early specimens which gradually changed to mild. He considered this moderate reaction as being of nonclinical importance. In subsequent similar studies, Feldmann and Nyborg $^{3}$ as well as Nagai and Imazeki ${ }^{4}$ working with rabbits, and Sperber ${ }^{5}$ in rats confirmed Mitchell's findings. The reaction to amalgam was also studied histologically on the palatal mucosa, ${ }^{6,7}$ on mandibular bone, ${ }^{8}$ on gingiva, ${ }^{9-11}$ and on dental pulp. ${ }^{12-15}$

However, a review of the dental literature has not revealed a histologic study of the effects

Received for publication July 27, 1976

Accepted for publication October 15, 1976.

This work was supported by the Medical Research Service of the Veterans Administration.

For reprints address: Dr. Carlos E. Nasjletỉ, Dental Research Section, Veterans Administration Hospital, 2215 Fuller Road, Ann Arbor, Michigan 48105, USA.

* Ralston Purina Co., St. Louis, Mo.

$\dagger$ S. S. White, Dental Products Division of Pennwalt Corp., Philadelphia, Pa.

$\ddagger$ The Toothmaster Co., Racine, Wi. of silver amalgam upon the periodontal membrane. The present study attempts to evaluate the periodontal membrane reaction to amalgam restorations. It involves a histopathologic evaluation of the periodontal membrane of in. tentionally reimplanted teeth carrying amalgam restorations in the middle third of their roots, by using the same experimental model that was successfully applied to study the ef. fects of acrylic restorations on the periodontal membrane of monkeys. ${ }^{16,17}$

\section{Materials and Methods}

Eight healthy male rhesus monkeys ( $M a$ caca mulatta) were used for this study. All the monkeys were adults and were approximately the same size and weight. The monkeys were given Purina Monkey Chow* and water ad libitum before and during the experimental period. A step-by-step sequence of the methods used for tooth reimplantation was reported previously from this laboratory ${ }^{16}$ Briefly, after extraction, the left maxillary central incisors were treated endodontically with zinc oxideeugenol paste and gutta percha points. Subsequently, in these treated teeth, cavities were prepared and filled with conventional amalgam. The cavities were placed on both the distal and the mesial aspects of the roots approximately half way between the cementoenamel junction and the apex. The cavities were prepared with a 588 carbide bur and were made approximately $3 \mathrm{~mm}$ in diameter and $2 \mathrm{~mm}$ deep. No further attempt was made to smooth the walls of the cavities. They were packed with amalgam using New True Dentalloy $\dagger$ with a 1:1 mercury-alloy ratio. Each mix contained two pellets $(800 \mathrm{mg}$ ) of the alloy and two drops $(800 \mathrm{mg})$ of the mercury. Trituration was performed for $30 \mathrm{sec}$ with a Tooth Master Amalgamator in a Caulk capsule with a plastic pestle. The mass was mulled for $5 \mathrm{sec}$ in the capsule without the pestle. The 


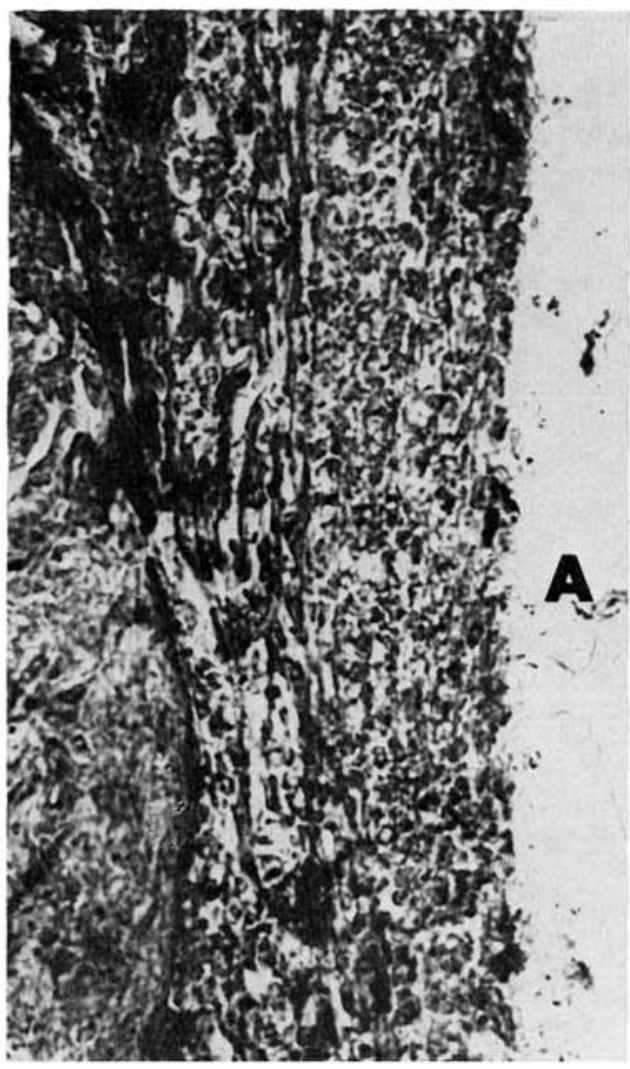

Fig 1.-Amalgam site of a seven-day specimen. Adjacent to the amalgam (A) the inflammatory infiltrate consisted mainly of polymorphonuclear leukocytes and abundant erythrocytes that derived from the blood clot formed as a consequence of reimplantation surgery. (Mallory's stain; orig mag $\times 450$.)

amalgam mass was divided into 5 parts. Thev were packed one at a time starting with the small end of the Eames \#1 plugger, and finishing with the large end of the Eames \#2 plugger. A stainless steel Ward's C Carver was used to carve the fillings. Four increments were used to fill the cavity, which was done in less than $3 \mathrm{~min}$ from the beginning of the trituration to the carving of the fillings. The teeth were immediately reimplanted. Each tooth was at most 1 hour out of its socket. Immobilization of the tooth was achieved by cementing a common metal inlay into previously prepared cavities both in the right and left central incisors. The monkeys received a daily doses of $100 \mathrm{mg}$ of Cosa Terramycin§ dis-

$\S$ Dept. Veterinary Medicine, Pfizer, Inc., New York, NY.

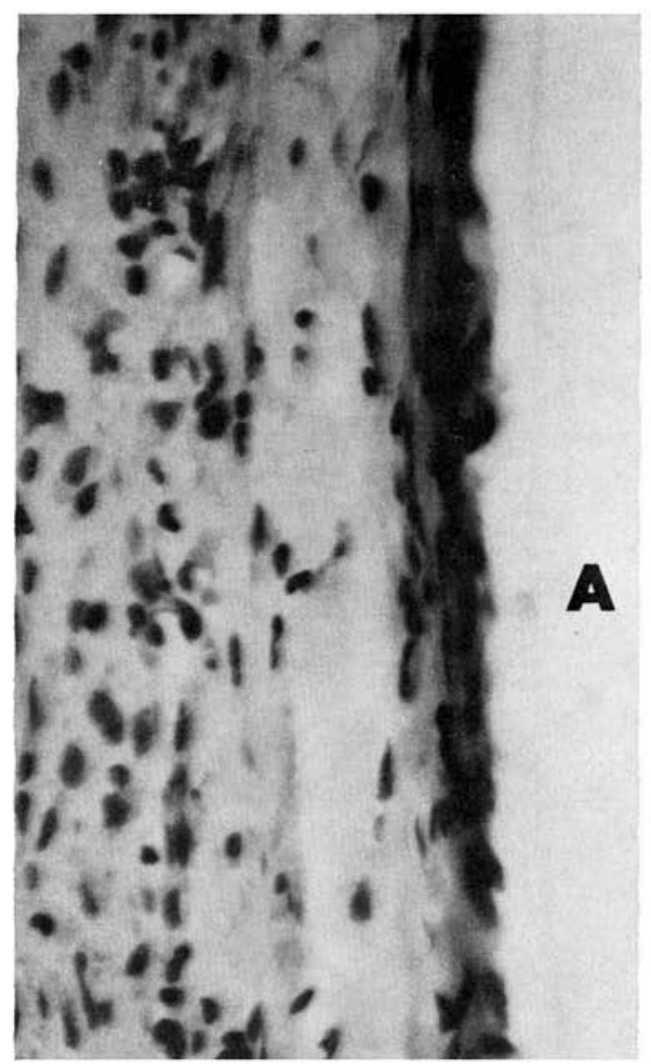

FIg 2.-Amalgam site (A) of a 30-day specimen. The healing process progressed to the formation of a thin pseudocapsule which consisted mainly of elongated fibrocytes. Note that the periodontal tissues exhibited a mild inflammatory infiltrate. (Hemotoxylin and eosin stain; orig mag $\times 450$.)

solved in water for the first five days after surgery. The monkeys were sacrificed postoperatively at $7,15,30,60,90,120,150$, and 180 days. The maxillary incisors with the surrounding bone and soft tissues were excised in block sections. They were fixed in $10 \%$ buffered formalin solution and were decalcified in formic acid. After decalcification, the amalgam retorations were removed from their beds to avoid tearing the surrounding tissues in the process of sectioning. The decalcified, paraffin-embedded tissues were sectioned at 5 to $7 \mu$ and stained with hematoxylin and eosin. as well as with Mallory's and periodic acid-Schiff stain, for histological examination.

\section{Results}

The histopathological evaluation of the 
periodontal tissues adjacent to the amalgam restoration gave the following findings. In seven-day specimens, the periodontal tissues exhibited a severe disorganization with hyaline degeneration and edema. The inflammatory infiltrate consisted mainly of polymorphonuclear leukocytes, and abundant erythrocytes that derived from the blood clot formed as a consequence of the reimplantation surgery (Fig 1). In fifteen-day specimens, the inflammatory reaction persisted in the periodontal membrane with edema and disoriented collagen fibers. A moderate inflammatory infiltrate containing polymorphonuclear leukocytes and mononuclear cells, was present in the periodontal tissues. A thin fibrinous layer, 10 to $15 \mu$ in thickness, interposed between the amalgam surface and the periodontium. In 30-day specimens, the healing process progressed to the formation of a thin, well-defined pseudocapsule of 20 to $40 \mu$ in thickness. This capsule consisted mainly of elongated fibrocytes and isolated the amalgam from the adjacent periodontal tissues ( Fig 2). These tissues exhibited a mild chronic inflammatory infiltrate.

In 60-day specimens, a more advanced pseudocapsule of 40 to $60 \mu$ in thickness developed (Fig 3), that filled almost completely the periodontal membrane space. The periodontal fibers attached to the bone run parallel to the pseudocapsule, reinforcing this structure (Fig 4). There was no evidence of inflammatory infiltraton in these tissues. In 90- to 180-day specimens, the findings were similar to those of

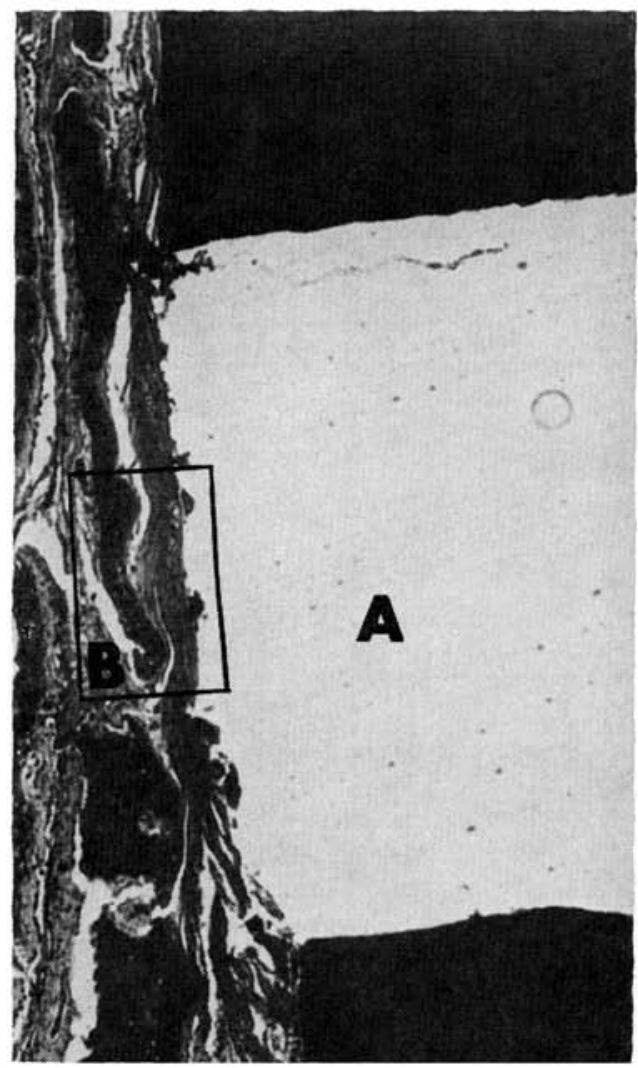

FIG 3.-Amalgam site (A) of a 60-day specimen. A more advanced pseudocapsule of 40 to $60 \mu$ in thickness developed that filled almost completely the periodontal membrane space. (Mallory's stain; orig mag $\times 62.5$.)

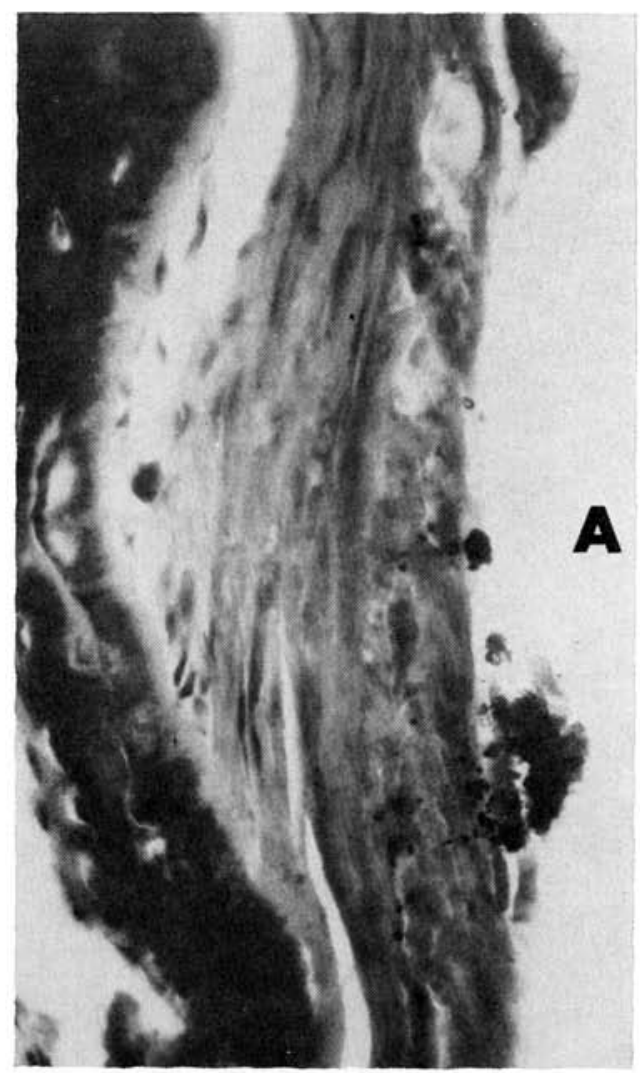

Fig 4.-High power view of area (B) in Fig 3. The periodontal fibers attached to the bone run parallel to the pseudocapsule. Note that there is no inflammatory infiltration in these tissues. (Mallory's stain; orig mag $\times$ 450.) 
60-day specimens. However, a better organized pseudocapsule was the consistent finding, with no inflammatory evidence in the tissues.

It was noted that no inflammatory cells were present within the confines of the periodontal membrane in areas coronally and apically to the amalgam restorations in 7- to 180day specimens. In general, the healing of the reimplanted teeth in those areas followed a pattern similar to that previously described. ${ }^{18}$ The marginal tissues reattached to the teeth in seven days. The connective tissues fibers were restored in fifteen days, attaching to cementum, but without displaying their normal arrangement and maturity. Complete maturity was only seen in the six-month specimens. At this time, new cementum and bone were deposited that covered areas of previous resorption, and no areas of ankylosis were found.

\section{Discussion}

The healing process of the periodontal membrane, as a result of reimplantation surgery, was uneventful and coincided with sequential stages already described. ${ }^{16-18}$ However, the area of the periodontal membrane adjacent to the amalgam restoration reacted in a different manner. The balanced biological substrate of the membrane was disrupted by the reactive capacity of the amalgam to produce the sequential inflammatory processes that culminated in the formation of a pseudocapsule. The reactivity of the amalgam was not intense enough to produce necrosis of the membrane, but was able to produce vascular and cellular responses that were still present in the 30-day specimens. Comparing the healing process with that which followed the reimplantation of a tooth, ${ }^{18}$ a delay of approximately two weeks was observed. The sequential stages of the periodontal membrane response to an amalgam restoration indicated that: (1) an acute inflammatory reaction developed in seven days; (2) this reaction changed to a chronic inflammatory process with the formation of a pseudocapsule in 30 days; and (3) there was no evidence of inflammatory filtration in the pseudocapsule or in the adjacent tissues in 60- to 180day specimens.

In this study, as well as in previous studies, ${ }^{1,5,8}$ the presence of well-defined pseudocapsules in the periodontium of 60 - to 180 -day specimens is a good indication that the periodontal membrane cannct endure the influence of the silver amalgam and regain total nor- malcy until the inflammatory response to the filling has subsided. The pseudocapsule is neressary to assure the isolation of the amalgam restoration, and thus, to preserve the regained equilibrium of the internal medium in those tissues.

Regarding the reaction of gingival tissues to amalgam restorations, the general concensus since the classical study by Zander ${ }^{9}$ is that this filling material, as well as any other restorative plastic material, elicits a chronic inflammatory response. This response is similar to that observed as a response to calculus. ${ }^{10}$ However, it seems to be the plaque retentive ability of the amalgam, the factor that governs the gingival inflammatory response. Barryckman and Wawerka $^{11}$ studied the effects of amalgam on the gingiva of germ-free and conventional Fisher 344 rats, and demonstrated that amalgam per se did not cause inflammation in the germ-free animals, while the bacterial plaque accumulated on the amalgam restorations of the conventional animals elicited the inflammatory gingival response.

Investigating the indirect effect of amalgam restorations on the pulp, Manley ${ }^{12}$ and Massler ${ }^{13}$ concluded that this material produced temporary changes in the odontoblastic layer and a round cell infiltration in the adjacent tissues. These same histopathological findings have been interpreted in a different manner by other authors ${ }^{14,15}$ who, through independent studies, found that it was either the force of compressing the amalgam into the cavity or the thermal conductive capacity of the material, that provoked the response of the pulp tissues.

From the above considerations, it seems reasonable to agree that in the absence of bacteria, silver amalgam is a safe restorative material, well tolerated by the surrounding tissues. Thus, in cases of retrograde restorations, silver amalgam will produce an initial localized inflammation in the periodontal tissues that subsides subsequently. A fibrous capsule will be formed bonding the restoration, with healthy periodontal tissues. The apparent condition required for the formation of a pseudocapsule is that the silver amalgam needs to be embedded in a tissue or be in direct contact with the internal medium.

The reason for the delayed healing of the periodontal tissues in contact with the amalgam compared to the healing of other areas of the reimplanted tooth is open to speculation. It is possible the internal medium had oxidized the alloy to produce a chemical compound that 
might be toxic to the periodontal tissues. Conversely, it has been postulated that different alloy-to-mercury ratios are capable of producing different tissue changes on the palatal mucosa of the rat.6,7

\section{Conclusions}

The purpose of the present study was to evaluate the histopathological response of the periodontal membrane of intentionally reimplanted teeth carrying silver amalgam restorations in the middle third of their roots. Eight adult, healthy male rhesus monkeys were used. In each monkey, the left maxillary central incisor was extracted and endodontically treated. Cavities were prepared on the mesial and distal middle third of the roots, then filled with conventional amalgam. Subsequently, the teeth were immediately reimplanted. The monkeys were sacrificed postoperatively at $7,15,30,60$, $90,120,150$, and 180 days. The maxillary incisors with the surrounding bone and soft tissues were prepared for histopathological examination.

The healing process of the periodontal membrane, as a result of reimplantation, was uneventful and coincided with sequential stages already described in the literature. ${ }^{16-18}$ The periodontal membrane response to the amalgam restorations showed that: (1) an acute inflammatory reaction developed in seven days; (2) this reaction changed to a chronic inflammatory process with the formation of a pseudocapsule in 30 days; and (3) there was no evidence of inflammatory infiltration in the pseudocapsule or in the adjacent tissues in 60to 180 -day specimens.

It was concluded that conventional amalgam is a safe restorative material, well tolerated by the surrounding periodontal tissues.

\section{References}

1. Dixon, C.M., and Rigkert, U.G.: Tissue Tolerance to Foreign Materials, JADA 20: 1458-1472, 1933.

2. Mrtahell, D.F.: The Irritational Qualities of Dental Materials, JADA 59:954-966, 1959.

3. Feldmann, G., and Nyborg, H.: Tissue Reactions to Root Filling Materials. I. Comparison Between Gutta Percha and Silver Amalgam Implanted in Rabbit, Odontologisk Revy, 13:1-14, 1962.
4. NAGAI, K., and ImazeKI, T.: Correlational Study Between Metallographical Findings of Metals and Their Tissue Reactions in Vital Body, I Nihon Univ Sch Dent 2:66-74, 1959.

5. Sperber, G.H.: Biological Reactions to Experimental Dental Amalgams, $J$ Dent Res 45(1):99-105, 1966.

6. Butaher, E.O.; Sarna, R.; and KitnasBERG, J.: Effects of Restorative Materials on the Palatal Mucosa of the Rat, $J$ Pros Dent $14(4): 682-686,1964$.

7. Butcher, E.O., and Klingsberg, J.: Age Changes and Wound Healing in the Oral Tissues, Ann Dent 23(3):84-85, 1964.

8. Eger, W., and Fischer, C.H.: Tierexperimentelle und Klinische Untersuchungen uber die Gewebsreaktion der Amalgame in Unmittebarem Kontakt mit dem Knochenmark (I. Teil), Dtsch zahnarztl Z 11:499, 1956.

9. ZANDER, H.A.: Effect of Silicate Gement and Amalgam on the Gingiva, JADA 55:11-15, 1957.

10. App, G.R.: Effect of Silicate, Amalgam, and Gast Gold on the Gingiva, J Pros Dent 11 (3) :522-532, 1961.

11. Barrickman, R.W., and WaWerka, G.: Effect of Amalgam on Gingiva of Germ-free and Conventional Animals, $J$ Dent Res 54 (Special Issue A) Abst \# 72, Feb 1975.

12. MANLEy, E.B.: Investigations into Early Effects of Various Filling Materials on the Human Pulp, Dent Record 62:1-11, 1942.

13. MAssler, M.: Effects of Filling Materials on the Pulp, J Tennessee Dent Assoc 35: 353-374, portrait Oct 1955.

14. Auvenshine, R.C. and Eames, W.B.: Pulpal Response of Monkey to Modifications of a Bisphenol A Composite Resin and Cement, J Dent Res 51:1062-1066, 1972.

15. Swerdoow, H., and Stanlex, H.E.: Response of the Human Dental Pulp to Amalgam Restorations, Oral Surg 15:499-508, 1962.

16. Castelli, W.A.; Nasjletr, G.E.; Huelke, D.F.; and Draz-Perez, R.: Revascularization of the Periodontium after Tooth Grafting in Monkeys, $J$ Dent Res 50 (2):414-421, 1971.

17. Nasjleti, C.E.; Casteli, W.A.; and KelLER, B.E.: Effects of Acrylic Restorations on the Periodontium of Monkeys, J Dent Res $51(5): 1383-1387,1972$.

18. Nas Jleti, C.E.; Caffesse, R.G.; Casteli, W.A.; and Hoke, J.A.: Healing after Tooth Reimplantation in Monkeys, Oral Surg 39 (3) : 361-375, 1975. 